www.nature.com/jhg

\title{
Polymorphisms and haplotypes in TLR9 and MYD88 are associated with the development of Hodgkin's lymphoma: a candidate-gene association study
}

\author{
Vassiliki Mollaki ${ }^{1}$, Thomas Georgiadis ${ }^{2}$, Anna Tassidou $^{3}$, Maria Ioannou ${ }^{4}$, Zoe Daniil ${ }^{5}$, Aggeliki Koutsokera ${ }^{5}$, \\ Aphrodite A Papathanassiou ${ }^{6}$, Elias Zintzaras ${ }^{6,7}$ and George Vassilopoulos ${ }^{1,8}$
}

Toll-like receptors (TLRs) and myeloid differentiation primary response protein 88 (MYD88) gene polymorphisms may be involved in the pathogenesis of Hodgkin's lymphoma (HL) through altered immunoregulatory and inflammatory responses. A candidate-gene association study was conducted to investigate the association between $T L R 9-1237 T>C, T L R 92848 \mathrm{~A}>\mathrm{G}$, MYD88 -938C $>$ A and MYD88 1944C $>$ G gene polymorphisms and the risk for $\mathrm{HL}$. The impact of haplotypes was also examined. The study showed that carriership for $-1237 \mathrm{C}$ and $2848 \mathrm{~A}$ was associated with an increased risk for $\mathrm{HL}$ (odds ratio $(O R)=2.53(1.36-4.71)$ and $O R=6.20(1.3-28.8))$. The MYD88 polymorphisms produced nonsignificant results. The estimated frequencies of the TLR9/1237C-2848A and MYD88/938C-1944G haplotypes were also significantly different between HL and controls $(P<0.01)$. In addition, a significant difference between HL and controls was observed for the TLR9/1237C-TLR9/ 2848A-MYD88/938C-MYD88/1944C haplotypes $(P<0.01)$. In conclusion, our study showed that TLR polymorphisms, and TLR9 and MYD88 haplotypes are related to the development of HL. Journal of Human Genetics (2009) 54, 655-659; doi:10.1038/jhg.2009.90; published online 11 September 2009

Keywords: gene; Hodgkin's lymphoma; HL; MYD88; polymorphism; TLR9

\section{INTRODUCTION}

Hodgkin's lymphoma (HL) is an uncommon neoplasm with an ageadjusted incidence of $2.5-3.1$ per $10 \mathrm{E} 5$ in the Western world. ${ }^{1,2}$ Involved lymph nodes show an inflammatory cellular background and rare Reed Sternberg (RS) cells, which are the malignant cells of HL. The pathogenesis of HL remains unclear. A transcription factor that has been implicated in the pathogenesis of HL is nuclear factor$\kappa \mathrm{B}(\mathrm{NF}-\kappa \mathrm{B})$, a pleiotropic mediator of inflammation. Strong constitutive NF- $\kappa \mathrm{B}$ activity is a common feature of $\mathrm{HL}$ cell lines ${ }^{3}$ and is required for the proliferation and survival of RS cells. ${ }^{3}$ However, the cause of NF-kB triggering is still elusive, but there is evidence that it may be linked to the Epstein Bar Virus (EBV), a herpes virus that has been associated with HL. ${ }^{4-9}$ In addition, one of the EBV proteins, the Latent Membrane Protein 1 (LMP1), activates NF- $\kappa B$, stimulates cell proliferation and prevents apoptosis. ${ }^{10}$

Family studies have shown that inherited factors may also have a role in the development of HL; individuals related to HL patients have more than a three-fold increased risk of developing HL, as shown by population ${ }^{11-15}$ and twin studies. ${ }^{16}$ Factors that are involved in EBV recognition and NF-kB activation are the Toll-like receptors (TLRs). Specifically, TLR9 recognizes viral CpG islands and, once activated, it signals through myeloid differentiation primary response protein 88 (MYD88) and leads to NF- $\kappa B$ activation. ${ }^{17-19}$ Considering the importance of TLRs in NF- $\mathrm{KB}$ activation, one could hypothesize that these receptors may have a role in the abundant inflammatory background present in HL. To test this hypothesis, we chose to examine whether genetic variations in TLR9 and MYD88 are associated with the development of HL. Previous studies in $\mathrm{HL}^{20}$ showed an odds ratio (OR) of 0.82 for TLR9-1237C that was of borderline significance, whereas weak associations were also detected for follicular lymphoma and chronic lymphocytic leukemia.

TLR9 is located on chromosome $3 \mathrm{p} 21.3 ;^{21}$ it consists of two exons and two single-nucleotide polymorphisms (SNPs) define the four most common haplotypes in Caucasians. ${ }^{22}$ These include the $-1237 \mathrm{~T}>\mathrm{C}(\mathrm{dbSNP}$ rs5743836) and the synonymous $2848 \mathrm{~A}>\mathrm{G}$ (P545P) (dbSNP rs352140) SNP located in exon 2. TLR9 is in close proximity to the MYD 88 gene, which is located on chromosome $3 \mathrm{p} 22$ and consists of five exons. ${ }^{23}$ The $-938 \mathrm{C}>\mathrm{A}$ SNP (dbSNP rs4988453)

${ }^{1}$ Genetics and Gene Therapy Division, BRFAA, Athens, Greece; ${ }^{2}$ Pathology Laboratory, Hygeia Hospital, Athens, Greece; ${ }^{3}$ Haematopathology Laboratory, Evangelismos Hospital, Athens, Greece; ${ }^{4}$ Pathology Laboratory, University of Thessaly Medical School, Larissa, Greece; ${ }^{5}$ Department of Respiratory Medicine, University of Thessaly Medical School, Larissa, Greece; ${ }^{6}$ Department of Biomathematics, University of Thessaly School of Medicine, Larissa, Greece; ${ }^{7}$ Department of Medicine, The Institute for Clinical Research and Health Policy Studies, Tufts Medical Center, Tufts University School of Medicine, Boston, MA, USA and ${ }^{8}$ Division of Haematology, University of Thessaly Medical School, Larissa, Greece

Correspondence: Dr G Vassilopoulos, Genetics and Gene Therapy Division, Biomedical Research Foundation of the Academy of Athens, 4 Soranou Efesiou Str, Athens-115 27, Greece. 
and the 1944C $>$ G (dbSNP rs4988457) SNP define the two most common haplotypes in Caucasians. ${ }^{24}$ In this analysis, we undertook a gene-candidate association study to investigate whether the abovementioned polymorphisms contribute to the risk of HL.

\section{MATERIALS AND METHODS}

\section{Subjects}

A total of 90 formalin-fixed paraffin-embedded tissue sections collected from HL patients were analyzed from the Pathology Laboratories of Hygeia Hospital (Athens, Greece), the Evaggelismos Hospital (Athens, Greece) and from the University Hospital of Larissa (Larissa, Greece). All patients were of Caucasian origin and met the World Health Organization criteria for classic HL. Peripheral blood samples were obtained from 92 healthy subjects from the University Hospital of Larissa (Larissa, Greece), after receiving informed consent. The control subjects were healthy individuals of Caucasian origin, with no known history of HL or any other disorder.

\section{SNP genotyping}

Case and control subjects were genotyped for the TLR9 (GenBank Accession No. NM_017442) and MYD88 (GenBank Accession No. NM_002468) SNPs of interest. After consecutive attempts, genotyping was successful for $86 \mathrm{HL}$ cases and for 84 control subjects for the TLR9 $-1237 \mathrm{~T}>\mathrm{C}$ SNP, for 90 cases and 90 controls for the TLR9 2848A $>$ G SNP, for 90 cases and 87 controls for the MYD88 -938C >A SNP and for 86 cases and 89 controls for the MYD88 1944C > G SNP. PCR was used to amplify DNA fragments encompassing SNPs of interest in a typical reaction containing the $1 \times$ PCR buffer, $\sim 30$ ng genomic DNA, $1-1.5 \mathrm{~mm} \mathrm{MgCl}_{2}, 0.2 \mathrm{~mm}$ dNTPs, $0.2 \mathrm{~mm}$ of each primer and 1.25 Units Go Taq Flexi Polymerase (Promega, Southampton, UK). Samples were denatured for $5 \mathrm{~min}$ at $96^{\circ} \mathrm{C}$ and subjected to 35 cycles of denaturation at $96^{\circ} \mathrm{C}$ for $1 \mathrm{~min}$, annealing at $56-64^{\circ} \mathrm{C}$ (depending on the primers used) for $1 \mathrm{~min}$ and extension at $72^{\circ} \mathrm{C}$ for $1 \mathrm{~min}$, followed by an extension step at $72^{\circ} \mathrm{C}$ for $5 \mathrm{~min}$.

The TLR9 $-1237 \mathrm{~T}>\mathrm{C}$ genotypes were determined by amplification of a $456 \mathrm{bp}$ fragment of the $5^{\prime}$-flanking region of TLR9 using primers $5^{\prime}$-AAG AAG CTG ACA TTC CAG CAG GG-3' (forward) and 5'-CTA GGT CCC TCC TCT GCT CAG AC- $3^{\prime}$ (reverse) at $64^{\circ} \mathrm{C}$ annealing, followed by $B s t N I$ digestion of the PCR product. Digestion resulted in fragments of 31, 38, 48, 89, 112 and $186 \mathrm{bp}$ in the presence of the Tallele, and in fragments of 31,38, 48, 89, 112 and $138 \mathrm{bp}$ in the presence of the $\mathrm{C}$ allele. The TLR9 2848A $>\mathrm{G}$ genotypes were identified by amplification of a $371 \mathrm{bp}$ fragment of exon 2 using primers 5'-TGG ATC TGC CAC GGA ACA ACC-3' (forward) and 5'-CAG CGA CGT ACT GCA GAG CTG-3' (reverse) at $62^{\circ} \mathrm{C}$ annealing, followed by BstUI digestion. Digestion of the PCR product resulted in fragments of 226 and $145 \mathrm{bp}$ in the presence of the $\mathrm{G}$ allele, and $371 \mathrm{bp}$ in the presence of the A allele. The MYD $88-938 \mathrm{C}>$ A genotypes were determined by PCR amplification of a $503 \mathrm{bp}$ fragment of the $5^{\prime}$-flanking region of MYD88 using primers $5^{\prime}$-GCA GCC AGG ACC GCT TACT GC T-3' (forward) and 5'-GCA CGT GGC CTT GCC CTT GCC CTT TAG G-3' (reverse) at $62{ }^{\circ} \mathrm{C}$ annealing, followed by Bsr digestion of the PCR product. The expected fragment sizes after digestion were 23, 97, 165 and $218 \mathrm{bp}$ in the presence of the $\mathrm{C}$ allele, and 97,165 and $241 \mathrm{bp}$ in the presence of the A allele. The MYD88 1944C > G genotypes were identified by amplification of a $448 \mathrm{bp}$ fragment of intron 3 using primers $5^{\prime}$-GCC CCA GCG ACA TCC AGT TTG TG-3' (forward) and $5^{\prime}$-TCT TGC CAG AGC AGG GTT GAG CTT-3' (reverse) at $56^{\circ} \mathrm{C}$ annealing, followed by Cac8I digestion. Digestion of the PCR products resulted in fragments of 92, 135 and $221 \mathrm{bp}$ in the presence of the $\mathrm{G}$ allele, and in fragments of 135 and $313 \mathrm{bp}$ in the presence of the C allele. At least $10 \%$ of the samples were randomly selected as an internal control for repeated genotyping.

\section{Data analysis}

The genotypes were tested for Hardy-Weinberg (HW) equilibrium and the loci were tested for linkage disequilibrium using exact tests according to Weir. ${ }^{25,26}$ The haplotype frequencies were estimated and compared using PHASE v2.1 (Seattle, WA, USA) (http://www.stat.washington.edu/stephens/). The disequilibrium and correlation coefficients were estimated according to Weir. ${ }^{26}$ The genotype distribution, allele contrast and the dominant model (risk allele carriers) of the HL patients was compared with the control group using a log- linear model. ${ }^{27}$ The comparisons were expressed in terms of OR unadjusted and adjusted for age and sex. A $P$-value of $<0.05$ was considered statistically significant.

\section{RESULTS}

Demographic characteristics of the study population

A total of 91 cases and 92 controls were analyzed in this study. The mean age ( \pm s.d.) was $42.9 \pm 18.5$ and $35.5 \pm 10.1$ years for cases and controls, respectively; there were $44(50.6 \%)$ males and 43 (49.4\%) females in the case group, whereas the control group comprised 27 (29.3\%) males and 65 (70.7) females. HL samples were of the following histological subtypes: nodular sclerosis ( 73 cases), mixed cellulary (15 cases) and lymphocyte rich (3 cases). The control subjects were younger and comprised a higher percentage of females than did the cases.

\section{Genotype distributions and study quality}

The distributions of the TLR9 - 1237T > C, TLR9 2848A > G, MYD88 $-938 \mathrm{C}>\mathrm{A}$ and MYD88 1944C $>\mathrm{G}$ genotypes in both cases and controls are shown in Table 1. Significant differences were detected in the distribution of genotypes of the two TLR polymorphisms between cases and controls $(P=0.01$ for TLR9 $-1237 \mathrm{~T}>\mathrm{C}$ and $P=0.03$ for TLR9 $2848 \mathrm{~A}>\mathrm{G}$ ). In contrast, there were no differences for the MYD88 polymorphisms $(P=0.16$ for MYD88 $-938 \mathrm{C}>\mathrm{A}$ and $P=0.25$ for MYD88 1944C $>G$ ). No individuals homozygous for the mutant allele in either cases or controls were present for the MYD88 polymorphisms.

The controls were in HW equilibrium for all investigated polymorphisms, indicating the lack of stratification and/or genotyping error $^{28}(P=0.11$ for TLR9 $-1237 \mathrm{~T}>\mathrm{C}, P=0.37$ for TLR9 2848A $>\mathrm{G}$, $P=0.99$ for MYD88 $-938 \mathrm{C}>\mathrm{A}$ and $P=0.60$ for MYD88 $1944 \mathrm{C}>\mathrm{G}$ ).

\section{Polymorphisms in TLR9 and association with HL}

Table 2 shows the association results for the TLR9 polymorphisms. The allele contrast showed that for the $-1237 \mathrm{C}$ allele there was a twofold risk for HL relative to the $-1237 \mathrm{~T}$ allele $(\mathrm{OR}=1.99(1.18-3.36))$. Furthermore, $-1237 \mathrm{C}$-carrier individuals were associated with a higher risk of HL unadjusted and adjusted for age and sex $(\mathrm{OR}=2.53$ (1.36-4.71) and $\mathrm{OR}=2.02$ (1.04-3.89), respectively).

With regard to the TLR9 $2848 \mathrm{~A}>\mathrm{G}$ polymorphism, the allele contrast produced a marginal association $(\mathrm{OR}=1.54(1.00-2.39))$.

Table 1 Distribution (in \%) of the TLR9 - 1237T >C, TLR9 2848A $>$ G, MYD88 -938 C $>$ A and MYD88 1944C $>$ G genotypes among cases and control subjects

\begin{tabular}{|c|c|c|c|c|}
\hline SNPS & Genotypes & Cases $(n=90)$ & Controls $(\mathrm{n}=92)$ & P-value \\
\hline \multirow[t]{3}{*}{ TLR9 $-1237 \mathrm{~T}>\mathrm{C}$} & TT & 43.5 & 66.7 & 0.01 \\
\hline & $\mathrm{TC}$ & 55.3 & 33.3 & \\
\hline & $\mathrm{CC}$ & 1.2 & 0 & \\
\hline \multirow[t]{3}{*}{ TLR9 2848 A > G } & $A A$ & 43.3 & 33.3 & 0.03 \\
\hline & $A G$ & 54.5 & 54.5 & \\
\hline & $\mathrm{GG}$ & 2.2 & 12.2 & \\
\hline \multirow[t]{3}{*}{ MYD88 $-938 C>A$} & $\mathrm{CC}$ & 90 & 82.8 & 0.16 \\
\hline & $\mathrm{CA}$ & 10 & 17.2 & \\
\hline & $\mathrm{AA}$ & 0 & 0 & \\
\hline \multirow[t]{3}{*}{ MYD88 1944C > G } & $\mathrm{CC}$ & 67.1 & 75.3 & 0.25 \\
\hline & CG & 32.9 & 24.7 & \\
\hline & GG & 0 & 0 & \\
\hline
\end{tabular}

Abbreviations: HL, Hodgkin's lymphoma; SNP, single-nucleotide polymorphism. The $P$-values for testing the association between genotype distribution of each SNP and susceptibility to $\mathrm{HL}$ are shown.

Bold values emphasize statistical significance. 
Table 2 Odds ratio (OR) and the corresponding 95\% confidence intervals (Cls) for testing the association between HL and SNPs of the TLR9 and MYD88 genes for the allele contrast and the dominant model

\begin{tabular}{|c|c|c|c|c|}
\hline SNP & Genetic contrast & OR $(95 \% \mathrm{Cls})$ & P-value & OR adjusted (95\% Cls) \\
\hline \multirow[t]{2}{*}{ TLR9 $-1237 \mathrm{~T}>\mathrm{C}$} & $C$ vs $T$ & 1.99 (1.18-3.36) & 0.01 & \\
\hline & Dominant for $\mathrm{C}$ & $2.53(1.36-4.71)$ & $<0.01$ & $2.02(1.04-3.89)$ \\
\hline \multirow[t]{2}{*}{ TLR9 $2848 \mathrm{~A}>\mathrm{G}$} & $A$ vs $G$ & $1.54(1.00-2.39)$ & 0.06 & \\
\hline & Dominant for $\mathrm{A}$ & $6.20(1.33-28.8)$ & 0.01 & $4.66(1.00-22.9)$ \\
\hline MYD88 $-938 C>A$ & $C$ vs $A$ & $1.77(0.75-4.16)$ & 0.28 & \\
\hline \multirow[t]{2}{*}{ MYD88 $1944 C>G$} & G vs $C$ & $1.40(0.77-2.56)$ & 0.36 & \\
\hline & Dominant for $\mathrm{G}$ & $1.47(0.76-2.84)$ & 0.25 & $1.38(0.68-2.78)$ \\
\hline
\end{tabular}

Abbreviations: HL, Hodgkin's lymphoma; SNP, single-nucleotide polymorphism.

The ORs adjusted for age and sex are also shown.

Bold values emphasize statistical significance.

Table $3 P$-values $/ D / r^{2}$ for testing linkage disequilibrium between pairs of SNPs for HL patients and controls (in brackets)

\begin{tabular}{lccc}
\hline & $T L R 9-1237 T>C$ & $T L R 92848 A>G$ & $M Y D 88-938 C>A$ \\
\hline TLR9 $2848 \mathrm{~A}>\mathrm{G}$ & $<0.01 / 0.11 / 0.01(0.35 / 0 / 0)$ & & \\
MYD88 $-938 \mathrm{C}>\mathrm{A}$ & $0.04 / 0.02 / 0(0.32 / 0.07 / 0)$ & $<0.01 / 0.02 / 0(0.63 / 0.07 / 0)$ & $0.47 / 0.78 / 0.39(<0.01 / 0.87 / 0.63)$ \\
MYD88 $1944 \mathrm{C}>\mathrm{G}$ & $0.05 / 0 / 0(0.62 / 0.02 / 0)$ & $0.06 / 0.08 / 0(0.78 / 0.01 / 0)$ &
\end{tabular}

Abbreviations: HL, Hodgkin's lymphoma; SNP, single-nucleotide polymorphism.

2848A carriers had an increased risk for HL, as the unadjusted OR was significant $(\mathrm{OR}=6.20(1.3-28.8))$; however, the adjusted $\mathrm{OR}$ was marginally significant $(\mathrm{OR}=4.66(1.00-22.9))$.

Polymorphisms in the MYD88 gene and association with HL Table 2 shows that the MYD88 polymorphisms produced nonsignificant results. The allele contrasts $-938 \mathrm{C}$ vs A and $1944 \mathrm{G}$ vs C were not significant $(\mathrm{OR}=1.77(0.75-4.16)$ and $\mathrm{OR}=1.40(0.77-2.56))$. In addition, 1944G carriers were not associated with increased risk of $\mathrm{HL}$ (unadjusted $\mathrm{OR}=1.47(0.76-2.84)$ and adjusted $\mathrm{OR}=1.38$ $(0.68-2.78))$.

TLR9 and MYD88 haplotype frequency in HL patients and control subjects

Table 3 shows the $P$-values, and the respective $D^{\prime}$ and $r^{2}$, for testing linkage disequilibrium between pairs of SNPs for HL patients and controls. In the patient population, TLR9 $-1237 \mathrm{~T}>\mathrm{C}$ was in linkage disequilibrium with TLR9 2848A $>\mathrm{G}(P<0.01)$, MYD88 $-938 \mathrm{C}>\mathrm{A}$ $(P=0.04)$ and MYD88 1944C $>\mathrm{G}(P=0.05)$. TLR9 2848A $>\mathrm{G}$ was also found in linkage disequilibrium with $M Y D 88-938 \mathrm{C}>\mathrm{A}(P<0.01)$ in HL patients. In controls, the two MYD88 polymorphisms were in linkage disequilibrium $(P<0.01)$ (Table 3$)$.

The distribution of the estimated haplotype frequency of the two TLR9 polymorphisms and the two MYD88 polymorphisms for the HL and controls is presented in Table 4. Regarding the TLR9 haplotypes, there was an overall significant difference between the HL and controls $(P=0.03)$. This difference was due to the 1237C-2848A haplotype (or the 1237T-2848G haplotype) $(P<0.01)$. For the MYD88 haplotypes, the overall difference was not significant $(P=0.20)$. However, the estimated frequency of the haplotype $938 \mathrm{C}-1944 \mathrm{G}$ was different in $\mathrm{HL}$ and controls; this difference might be due to the linkage disequilibrium with the TLR9 polymorphisms or because of the interaction between the two polymorphisms, given that the individual MYD88 polymorphisms were not significant.

When the estimated haplotypes of the four investigated polymorphisms were considered (Table 5), a significant difference between HL and controls was observed for the 1237T-2848G-938C-1944C and the
Table 4 Estimated haplotype frequencies for the two TLR9 SNPs ( TLR9 $-1237 \mathrm{~T}>\mathrm{C}$ and TLR9 2848A $>\mathrm{G}$ ) and the two MYD88 SNPs (MYD88 $-938 \mathrm{C}>\mathrm{A}$ and $M Y D 881944 \mathrm{C}>\mathrm{G}$ )

\begin{tabular}{|c|c|c|c|c|}
\hline & \multicolumn{2}{|c|}{ Haplotype frequency } & \multirow[b]{2}{*}{ P-value } & \multirow[b]{2}{*}{ P-value overall } \\
\hline & Cases & Controls & & \\
\hline \multicolumn{5}{|c|}{ TLR9 haplotype $\left(5^{\prime}-3^{\prime}\right)$} \\
\hline TG & 0.272 & 0.379 & $<0.01$ & 0.03 \\
\hline $\mathrm{TA}$ & 0.443 & 0.454 & 0.63 & \\
\hline CG & 0.025 & 0.020 & 0.83 & \\
\hline $\mathrm{CA}$ & 0.260 & 0.147 & $<0.01$ & \\
\hline \multicolumn{5}{|c|}{ MYD88 haplotype $\left(5^{\prime}-3^{\prime}\right)$} \\
\hline $\mathrm{CC}$ & 0.802 & 0.824 & 0.09 & 0.20 \\
\hline$C G$ & 0.144 & 0.088 & $<0.01$ & \\
\hline$A C$ & 0.039 & 0.0529 & 0.28 & \\
\hline$A G$ & 0.0139 & 0.0353 & 0.10 & \\
\hline
\end{tabular}

Abbreviation: SNP, single-nucleotide polymorphism.

The $P$-values for comparing each haplotype between cases and controls, and the $P$-values for comparing the difference overall the haplotypes are shown.

1237C-2848A-938C-1944C haplotypes $(P<0.01)$, further indicating the association of $1237 \mathrm{~T}$ and $2848 \mathrm{G}$ alleles (or allele carriers) with HL susceptibility.

\section{DISCUSSION}

This study investigated whether certain TLR9 and MYD88 gene polymorphisms were associated with the development of HL. Our results showed that the TLR9 $-1237 \mathrm{C}$ allele confers a two-fold increased risk of HL and that the TLR9 2848A allele increased HL risk by $\sim 4.5$-fold in the Caucasian population examined. None of the MYD88 SNPs analyzed (MYD88 -938C > A and MYD88 1944C>G) were found to alter the susceptibility to HL. The genotype distributions of the SNPs examined were all in HW in the control group, indicating no population stratification. Haplotype analysis also 
Table 5 Estimated haplotype frequencies for the four SNPs (TLR9 -1237 T $>$ C, TLR9 2848A $>$ G, MYD88 -938C $>$ A and MYD88 $1944 C>G)$

\begin{tabular}{|c|c|c|c|}
\hline \multirow[b]{2}{*}{ TLR9-MYD88 haplotype $\left(5^{\prime}-3^{\prime}\right)^{a}$} & \multicolumn{2}{|c|}{ Haplotype frequency } & \multirow[b]{2}{*}{ P-value } \\
\hline & Cases & Controls & \\
\hline TGCC & 0.176 & 0.290 & $<0.01$ \\
\hline TGCG & 0.039 & 0.032 & 0.63 \\
\hline TGAC & 0.015 & 0.022 & 0.52 \\
\hline TGAG & 0.010 & 0.024 & 0.25 \\
\hline TACC & 0.397 & 0.402 & 0.86 \\
\hline TACG & 0.063 & 0.035 & 0.11 \\
\hline TAAC & 0.009 & 0.015 & 0.54 \\
\hline TAAG & 0.002 & 0.013 & 0.26 \\
\hline CGCC & 0.041 & 0.037 & 0.85 \\
\hline CGCG & 0.007 & 0.002 & 0.46 \\
\hline CGAC & 0.002 & 0.0003 & 0.66 \\
\hline CGAG & 0.004 & 0.0008 & 0.57 \\
\hline CACC & 0.192 & 0.109 & $<0.01$ \\
\hline CACG & 0.031 & 0.014 & 0.21 \\
\hline CAAC & 0.009 & 0.001 & 0.24 \\
\hline CAAG & 0.002 & 0.003 & 0.83 \\
\hline
\end{tabular}

Abbreviation: SNP, single-nucleotide polymorphism.

The $P$-values for comparing each haplotype between cases and controls are shown.

Bold values emphasize statistical significance.

a TLR9 T-1237C/TLR9 A2848G/MYD88 C-938A/MYD88 C1944G.

showed that the distribution of the TLR9 1237C-2848A haplotypes were different between cases and controls.

Others have also examined the role of TLRs and particularly that of TLR9 gene polymorphisms in susceptibility to human diseases associated with altered immune responses and inflammation. Among the other TLR polymorphisms, Nieters et al. ${ }^{20}$ investigated the contribution of the TLR9 $-1486 \mathrm{~T}>\mathrm{C}$ and $-1237 \mathrm{~T}>\mathrm{C}$ SNPs to the development of lymphomas, including 115 cases of HL. A $20 \%$ decreased risk of all lymphomas was associated with the TLR9 $-1237 \mathrm{C}$ allele, but this was of borderline significance. In contrast to our study, no contribution of the $-1237 \mathrm{~T}>\mathrm{C}$ SNP to HL was found.

Although significant associations were detected in our study, the size was relatively small. However, candidate-gene association studies have the tendency to lack the power to detect a statistically significant association. For example, to achieve a power of $>80 \%$ to identify a modest genetic effect $(\mathrm{OR}=1.2)$ of a polymorphism present in $10 \%$ of individuals, a sample size of $\geqslant 10000$ subjects would be required. ${ }^{28}$ Therefore, the sample sizes required to predict association have to be far beyond what is currently available and no single institution or entity alone will be able to provide a reasonable number of patients. However, a future meta-analysis of multiple studies clearly has a role in offering an analysis with the potential for higher power. ${ }^{28,29}$ Future collaborative studies may allow the pooling of data, providing more power to detect significant associations. Furthermore, consortia performing gene-candidate or genome-wide association studies will be able to replicate the validity of the present findings.

This study was based on the hypothesis that genetic variations in TLR9 and MYD88, both of which have crucial roles in immunity and inflammation, could alter the downstream immunological responses after NF- $\kappa B$ activation. Given that increased NF- $\kappa B$ activation is a characteristic of HL cell lines and is required for the proliferation and survival of RS cells, ${ }^{3}$ TLR expression variability could participate in the pathogenesis of HL. This hypothesis was further supported by the fact that EBV has been repeatedly associated with the development of HL and that, on EBV infection, LMP1 constitutively transmits signals that activate NF- $\kappa B .{ }^{10}$

So far, the functional role of the TLR9 $-1237 \mathrm{~T}>\mathrm{C}$ polymorphism seems controversial. Deletions spanning the -3.2 to $-0.7 \mathrm{~kb}$ promoter region did not alter the TLR9 promoter activity, ${ }^{30}$ although the region was shown to be important for the Human Papillomavirus 16mediated inhibition of TLR9 expression. ${ }^{31}$ In silico analysis of the TLR9 promoter showed that the $-1237 \mathrm{~T}>\mathrm{C}$ change introduces a putative $\mathrm{c}-\mathrm{Rel} / \mathrm{NF}-\kappa \mathrm{B}$ transcription factor binding site; ${ }^{32}$ in vitro gene reporter assays showed that the TLR9 $-1237 \mathrm{~T}>\mathrm{C}$ SNP alters the TLR9 promoter activity, with the $-1237 \mathrm{~T}$ allele having a higher promoter activity $(P=0.018)$, suggesting the existence of regulatory elements across the polymorphic site $e^{33}$ and implying that the $-1237 \mathrm{C}$ allele is associated with lower TLR9 expression levels.

In conclusion, this study showed that a genetic variation in TLR9 may alter the susceptibility to HL. Although the functional significance, if any, of the TLR9 $-1237 \mathrm{~T}>\mathrm{C}$ and the TLR9 2848A $>$ G SNPs remains to be elucidated, our results suggest that TLR9 polymorphisms and TLR9 and MYD88 haplotypes may be involved in the pathogenesis of HL.

\section{ACKNOWLEDGEMENTS}

This work was supported in part by Grant EP.AN, YB-90 (GSRT, Athens, GR) and by CONSERT (LSHB 005242, EU).

1 Ries, L. A. G., Harkins, D., Krapcho, M., Mariotto, A., Miller, B. A., Feuer, E. J. et al. SEER Cancer Statistics Review, 1975-2005 (National Cancer Institute, Bethesda, MD, 2006) (http://seer.cancer.gov/statfacts/html/hodg.html).

2 Cartwright, R. A. \& Watkins, G. Epidemiology of Hodgkin's disease: a review. Hematol. Oncol. 22, 11-26 (2004).

3 Bargou, R. C., Emmerich, F., Krappmann, D., Bommert, K., Mapara, M. Y., Arnold, W. et al. Constitutive nuclear factor-kappaB-RelA activation is required for proliferation and survival of Hodgkin's disease tumor cells. J. Clin. Invest 100, 2961-2969 (1997).

4 Serraino, D., Franceschi, S., Talamini, R., Barra, S., Negri, E., Carbone, A. et al. Socioeconomic indicators, infectious diseases and Hodgkin's disease. Int. J. Cancer 47, 352-357 (1991).

5 Levine, R., Zhu, K., Gu, Y., Brann, E., Hall, I., Caplan, L. et al. Self-reported infectious mononucleosis and 6 cancers: a population-based, case-control study. Scand J. Infect. Dis. 30, 211-214 (1998).

6 Hjalgrim, H., Askling, J., Sorensen, P., Madsen, M., Rosdahl, N., Storm, H. H. et al. Risk of Hodgkin's disease and other cancers after infectious mononucleosis. J. Nat/ Cancer Inst. 92, 1522-1528 (2000).

7 Alexander, F. E., Daniel, C. P., Armstrong, A. A., Clark, D. A., Onions, D. E., Cartwright, R. A. et al. Gene clustering, Epstein-Barr virus Reed-Sternberg cell status and herpes virus serology in Hodgkin's disease: results of a case-control study. Eur. J. Cancer 31A, 1479-1486 (1995).

8 Grässer, F. A., Murray, P. G., Kremmer, E., Klein, K., Remberger, K., Feiden, W. et al. Monoclonal antibodies directed against the Epstein-Barr virus-encoded nuclear antigen 1 (EBNA1): immunohistologic detection of EBNA1 in the malignant cells of Hodgkin's disease. Blood 84, 3792-3798 (1994).

9 Gallagher, A., Armstrong, A. A., MacKenzie, J., Shield, L., Khan, G., Lake, A. et al. Detection of Epstein-Barr virus (EBV) genomes in the serum of patients with EBVassociated Hodgkin's disease. Int. J. Cancer 84, 442-448 (1999).

10 Hiscott, J., Kwon, H. \& Genin, P. Hostile takeovers: viral appropriation of the NFkappaB pathway. J. Clin. Invest 107, 143-151 (2001).

11 Goldgar, D. E., Easton, D. F., Cannon-Albright, L. A. \& Skolnick, M. H. Systematic population-based assessment of cancer risk in first-degree relatives of cancer probands. J. Natl Cancer Inst. 86, 1600-1608 (1994).

12 Westergaard, T., Melbye, M., Pedersen, J. B., Frisch, M., Olsen, J. H. \& Andersen, P. K. Birth order, sibship size and risk of Hodgkin's disease in children and young adults: a population-based study of 31 million person-years. Int. J. Cancer 72, 977-981 (1997).

13 Paltiel, O., Schmit, T., Adler, B., Rachmilevitz, E. A., Polliack, A., Cohen, A. et al. The incidence of lymphoma in first-degree relatives of patients with Hodgkin disease and non-Hodgkin lymphoma: results and limitations of a registry-linked study. Cancer $\mathbf{8 8}$, 2357-2366 (2000).

14 Shugart, Y. Y., Hemminki, K., Vaittinen, P., Kingman, A. \& Dong, C. A genetic study of Hodgkin's lymphoma: an estimate of heritability and anticipation based on the familial cancer database in Sweden. Hum. Genet. 106, 553-556 (2000). 
15 Goldin, L. R., Pfeiffer, R. M., Gridley, G., Gail, M. H., Li, X., Mellemkjaer, L. et al. Familial aggregation of Hodgkin lymphoma and related tumors. Cancer 100, 1902-1908 (2004).

16 Mack, T. M., Cozen, W., Shibata, D. K., Weiss, L. M., Nathwani, B. N., Hernandez, A. M. et al. Concordance for Hodgkin's disease in identical twins suggesting genetic susceptibility to the young-adult form of the disease. N. Engl. J. Med. 332, 413-418 (1995).

17 Parker, L. C., Prince, L. R. \& Sabroe, I. Translational mini-review series on Toll-like receptors: networks regulated by Toll-like receptors mediate innate and adaptive immunity. Clin. Exp. Immunol. 147, 199-207 (2007).

18 Bowie, A. G. \& Haga, I. R. The role of Toll-like receptors in the host response to viruses. Mol. Immunol. 42, 859-867 (2005).

19 Hemmi, H., Takeuchi, O., Kawai, T., Kaisho, T., Sato, S., Sanjo, H. et al. Toll-like receptor recognizes bacterial DNA. Nature 408, 740-745 (2000).

20 Nieters, A., Beckmann, L., Deeg, E. \& Becker, N. Gene polymorphisms in Toll-like receptors, interleukin-10, and interleukin-10 receptor alpha and lymphoma risk. Genes Immun. 7, 615-624 (2006).

21 Du, X., Poltorak, A., Wei, Y. \& Beutler, B. Three novel mammalian toll-like receptors: gene structure, expression, and evolution. Eur. Cytokine Netw. 11, 362-371 (2000).

22 Lazarus, R., Klimecki, W. T., Raby, B. A., Vercelli, D., Palmer, L. J., Kwiatkowski, D. J. et al. Single-nucleotide polymorphisms in the Toll-like receptor 9 gene (TLR9): frequencies, pairwise linkage disequilibrium, and haplotypes in three U.S. ethnic groups and exploratory case-control disease association studies. Genomics $\mathbf{8 1}$, 85-91 (2003).

23 Bonnert, T. P., Garka, K. E., Parnet, P., Sonoda, G., Testa, J. R. \& Sims, J. E. The cloning and characterization of human MyD88: a member of an IL-1 receptor related family. FEBS Lett. 402, 81-84 (1997).
24 Lazarus, R., Vercelli, D., Palmer, L. J., Klimecki, W. J., Silverman, E. K., Richter, B. et al. Single nucleotide polymorphisms in innate immunity genes: abundant variation and potential role in complex human disease. Immunol. Rev. 190, 9-25 (2002).

25 Lewis, P. O. \& Zaykin, D. Genetic Data Analysis: computer program for the analysis of allelic data release 1.0 (2001).

26 Weir, B. S. Genetic Data Analysis I/ (Sinauer Associates, Inc, Sunderland, MA, USA, 1996).

27 Baker, R. J. GLIM 3.77 Reference Manual (Numerical Algorithms Group Ltd, Oxford, UK, 1987).

28 Zintzaras, E. \& Lau, J. Synthesis of genetic association studies for pertinent genedisease associations requires appropriate methodological and statistical approaches. J. Clin. Epidemiol. 61, 634-645 (2008).

29 Zintzaras, E., Kitsios, G. D., Triposkiadis, F., Lau, J. \& Raman, G. APOE gene polymorphisms and response to statin therapy. Pharmacogenomics J. 4, 248-257 (2009).

30 Takeshita, F., Suzuki, K., Sasaki, S., Ishii, N., Klinman, D. M. \& Ishii, K. J. Transcriptional regulation of the human TLR9 gene. J. Immunol. 173, 2552-2561 (2004).

31 Hasan, U. A., Bates, E., Takeshita, F., Biliato, A., Accardi, R., Bouvard, V. et al. TLR9 expression and function is abolished by the cervical cancer-associated human papillomavirus type 16. J. Immunol. 178, 3186-3197 (2007).

32 Hamann, L., Glaeser, C., Hamprecht, A., Gross, M., Gomma, A. \& Schumann, R. R. Toll-like receptor (TLR)-9 promotor polymorphisms and atherosclerosis. Clin. Chim. Acta. 364, 303-307 (2006).

33 Novak, N., Yu, C. F., Bussmann, C., Maintz, L., Peng, W. M., Hart, J. et al. Putative association of a TLR9 promoter polymorphism with atopic eczema. Allergy 62, 766-772 (2007). 